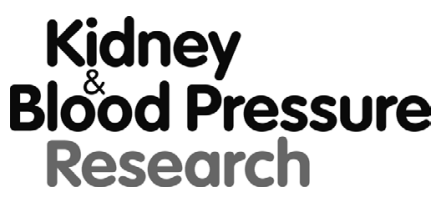

Kidney Blood Press Res 2018;43:1749-1764

DOI: $10.1159 / 000495394$

Published online: 23 November 2018

(C) 2018 The Author(s)

Published by S. Karger AG, Basel

Accepted: 14 November 2018

www.karger.com $/ \mathrm{kb}$

This article is licensed under the Creative Commons Attribution-NonCommercial-NoDerivatives 4.0 International License (CC BY-NC-ND) (http://www karger.com/Services/OpenAccessLicense). Usage and distribution tional License (CC BY-NC-ND) (http://Www.karger.com/Services/OpenAccessLicense). Usage and distribu

\title{
Inhibition of microRNA-376b Protects Against Renal Interstitial Fibrosis via Inducing Macrophage Autophagy by Upregulating Atg5 in Mice with Chronic Kidney Disease
}

\author{
Shufen Yang Rizwanguli Abdulla Chen Lu Ling Zhang \\ Nephrosis Department, Xinjiang Uygur Autonomous Region People's Hospital, Urumqi, P.R. China
}

\section{Key Words}

microRNA-376b • Autophagy-related gene 5 • Macrophages $•$ Kidney fibroblasts $•$ Autophagy

- Renal interstitial fibrosis • Chronic kidney disease

\begin{abstract}
Background/Aims: Renal interstitial fibrosis (RIF) is a common feature that facilitates the progression of chronic kidney disease (CKD), and emerging lines of evidence suggest that microRNA-376b (miR-376b) is capable of promoting RIF. In this study, we examined collagen deposition in kidney tissues, the autophagy and mitochondrial reactive oxygen species (ROS) of macrophages, and the apoptosis of kidney fibroblasts (KFBs) after the promotion or suppression of endogenous miR-376b in cultured macrophages and renal fibroblasts obtained from mice with CKD. Methods: FVB/N mice were prepared to establish a CKD model. A target prediction program and luciferase activity determination were used to confirm that autophagy-related gene 5 (Atg5) was a direct target of miR-376b. Macrophages and KFBs were isolated after the treatment to study the mechanisms and functions of miR-376b in relation to Atg5 in CKD. The autophagy level was determined, and KFB proliferation and apoptosis were assessed through MTT and EdU assays and flow cytometry, respectively. Results: Atg5 was confirmed as a direct target of miR-376b. miR-376b and Atg5 exhibited high and low expression in kidney tissues from mice with CKD. The mice treated with a miR376b inhibitor exhibited reduced collagen deposition, suppressed interstitial fibrosis, a higher level of autophagy, higher ROS production, enhanced apoptosis, and inhibited proliferation of KFBs, which suggested that the downregulation of miR-376b could exert beneficial effects on CKD through Atg5. Conclusion: miR-376b downregulation promotes macrophage autophagy
\end{abstract}




\section{Kidney Blood Pressure Research}

to relieve RIF by negatively regulating Atg 5 in mice with CKD. Thus, miR-376b might represent a potential focus of future investigations on treatments for CKD.

\section{Introduction}

Chronic kidney disease (CKD), which mainly arises from hypertension, diabetes mellitus and chronic glomerulonephritis, has attracted growing attention in recent years because it affects up to $13.4 \%$ of the population worldwide [1]. CKD can be defined as kidney dysfunction characterized by fibrillar collagen deposition lasting for at least 3 months [2, 3]. In addition, patients suffering from CKD may also experience unsatisfactory outcomes, including endstage renal disease progression and a significantly shortened lifespan [4]. Despite heavy social and economic burdens, CKD is usually diagnosed late, when the progression is not under control [5]. The Kidney Disease Improving Global Outcomes Conference has already appealed for global attention to the diagnosis and surveillance of CKD [6]. Thus, to address this problem, there is an urgent need to identify some possible biomarkers and mechanisms. Renal interstitial fibrosis (RIF) is a common pathway leading to the progressive loss of kidney function in CKD [7]. Accumulating studies have illustrated that macrophages play a role in RIF, and we thus speculate that macrophage autophagy can prevent RIF [8-10]. Understanding the molecular signaling mechanisms underlying the involvement of macrophage autophagy in RIF will lead to novel treatments of CKD.

MicroRNAs (miRNAs), a class of small noncoding RNAs with a length of approximately 20 to 25 nucleotides, have recently become promising therapeutic targets due to their function in regulating the expression of certain genes [11]. Some downregulated miRNAs regulate the disease course in a positive or negative manner [12]. In particular, miRNAs have been revealed as potential factors in the regulation of the kidney function in response to immunoreaction [13]. Additionally, autophagy, an evolutionarily conserved mechanism related to cell survival, is involved in CKD [14]. Abnormal autophagy function might be linked to kidney impairments to some extent [15]. A group of Chinese researchers revealed that miR-376b can mediate pathways related to autophagy, and autophagy-related gene 4 (Atg4) can be regulated by miR-376b [16]. Korkmaz et al. found that the upregulation of miR$376 \mathrm{~b}$ decreases the expression levels of Atg4C and Beclin-1, thus influencing the autophagy process [17]. In addition, miR-181A suppresses autophagy by targeting Atg5 [18]. Similarly, a recent study revealed that miR-9a-5p can regulate autophagy by binding to Atg5 [19]. Atg 5 contributes to the formation of the autophagosome in autophagy, and impairments in autophagosome formation might exert adverse effects on autophagy in mice [20]. In this context, we speculate that miR-376b might also regulate Atg5 to modulate autophagy. The inhibition of autophagy enhances renal fibrosis progression through the ablation of autophagy-specific genes; for instance, the Atg5-modulated inhibition of autophagy can promote the progression of renal fibrosis [21]. Because of the molecular mechanisms of miR$376 \mathrm{~b}$ and Atg5 regarding macrophage autophagy in RIF remain elusive, it is reasonable to hypothesize that miR-376b promotes CKD by regulating Atg5, which could help clinicians effectively plan the surgical and medical management of patients with CKD. Herein, we investigated the potential association among miR-376b, Atg5 and CKD in a mouse model.

\section{Materials and Methods}

Ethics Statement

This study was approved by the Animal Care and Use Committee of Xinjiang Uygur Autonomous Region People's Hospital. 


\section{Kidney Blood Pressure Research}

Yang et al.: miR-376b Targeting Atg5 Modulates RIF in CKD

\section{Model Establishment}

A total of $70 \mathrm{FVB} / \mathrm{N}$ male mice [22] (weighing $20 \mathrm{~g}$ and aged 6-8 weeks) were selected and randomly assigned into seven groups (each contained 10 mice): control, blank, negative control (NC), miR-376b mimic, miR-376b inhibitor, Atg5 short hairpin RNA (shRNA) and miR-376b inhibitor + Atg5 shRNA groups. The mice in the control group were normally fed, and the mice in the other six groups were intragastrically administered $100 \mathrm{mg} / \mathrm{kg}$ adenine every two days for one week. From the $2^{\text {nd }}$ to the $6^{\text {th }}$ week, the mice were given the same dose of adenine once a week and administered $1 \mu \mathrm{g} / \mathrm{kg}$ active vitamin D3 calcitriol through an intraperitoneal injection every two days. The mice were fed a high-phosphate diet containing $1.2 \%$ phosphorus [23] and were given free access to food at room temperature. The treatments were administered via intraperitoneal injections according to the group: control (normal mice without any treatment), blank (CKD mice without any treatment), NC (CKD mice treated with blank plasmid), miR-376b mimic (CKD mice treated with miR-376b mimic), miR-376b inhibitor (CKD mice treated with miR-376b inhibitor), Atg5 shRNA (CKD mice treated with Atg5 shRNA), and miR-376b inhibitor + Atg5 shRNA (CKD mice treated with both miR-376b inhibitor and Atg5 shRNA).

\section{Dual-Luciferase Reporter Assay}

The putative binding sites of miR-376b and Atg5 were predicted using a biological prediction website (https://cm.jefferson.edu/rna22/Interactive/). A dual-luciferase reporter assay was performed to verify whether Atg5 was a direct target gene of miR-376b. Target and mutant sequences were designed according to the binding sequences of the Atg5 mRNA 3' untranslated region (3'UTR) and miR-376b. Xho I and Not I restriction sites were introduced into the respective ends of the sequence. The synthesized sequence was cloned into the pUC57 carrier, and we identified positive clones. The recombinant plasmid was then identified by DNA sequencing, subcloned into the psiCHECK-2 carrier (VECT90299, Huayueyang Biotechnology (Beijing) Co., Ltd., Beijing, China) and transferred into Escherichia coli DH5 $\alpha$ cells for plasmid amplification. All the abovementioned plasmids were extracted using an Omega Plasmid Extraction Mini Kit (D1100-50T, Beijing Solarbio Life Sciences Co., Ltd., Beijing, China) following the kit's instructions. The cells were seeded into a six-well plate at a density of $2 \times 10^{5}$ cells per well. Once the cells adhered to the wall, the treatments were conducted as stated previously. Following treatment, the cells were cultured for $48 \mathrm{~h}$ and then collected. The luciferase activity of Atg5 3'UTR mediated by miR-376b was detected using a Dual-Luciferase Reporter Assay Detection Kit (D0010, Beijing Solarbio Life Sciences Co., Ltd., Beijing, China) according to the manufacturer's recommended method. A Glomax20/20 luminometer fluorescence detector (E5311, Shanxi Zhongmei Biotechnology Co., Ltd., Xi'an, Shanxi, China) was used to determine the fluorescence intensity. The experiment was repeated three times.

\section{Hematoxylin-Eosin (HE) Staining}

The mice were sacrificed through cervical dislocation. The obtained kidney tissues were fixed in $10 \%$ neutral formalin for at least $24 \mathrm{~h}$ and dehydrated conventionally through a gradient ethanol series $(70 \%$, $80 \%, 90 \%, 95 \%$ and 100\%; 1 min each time). The tissues were then transferred into a box containing xylene and cleared twice ( 5 min each time). The paraffin-embedded tissues were then sectioned into 4- $\mu \mathrm{m}$ slices for Masson staining, and serial sectioning $(5 \mu \mathrm{m})$ was conducted after the paraffin blocks were repaired. The sections were placed in an oven set to $80^{\circ} \mathrm{C}$ for $1 \mathrm{~h}$. After cooling, conventional dehydration using gradient ethanol and clearing in a box containing xylene were performed again. The sections were then washed, stained with hematoxylin for $4 \mathrm{~min}$ and re-washed. The sections were differentiated by hydrochloric ethanol for $10 \mathrm{~s}$, washed and soaked for $5 \mathrm{~min}$. Afterward, the sections were treated with ammonia for $10 \mathrm{~min}$, stained with eosin for $2 \mathrm{~min}$, dehydrated with a gradient ethanol series ( 1 min each time) and cleared twice ( 1 min each time) in a box containing xylene. The tissues were mounted with neutral balsam in a fume hood, and the histological changes in the kidney tissues were observed under an optical microscope.

\section{Masson Staining}

Dewaxed slices $(4 \mu \mathrm{m})$ were fixed in Bouin's Fixative Solution (Beijing Baiaolaibo Technology Co., Ltd., Beijing, China) for $30 \mathrm{~min}$ and washed under running water for $1 \mathrm{~min}$. The nuclei were stained with hematoxylin for $10 \mathrm{~min}$ and washed under running water for $30 \mathrm{~s}$. The slices were stained with Ponceau red dye liquor (WB1006-3, Shanghai Jingke Chemical Technology Co., Ltd., Shanghai, China) for 10-20 min. The 


\section{Kidney Blood Pressure Research}

specimens were washed under running water for $1 \mathrm{~min}$, treated with 1\% phosphomolybdic acid (WB10064, Shanghai Jingke Chemical Technology Co., Ltd., Shanghai, China) for 3-5 min, stained with 2\% aniline blue (WB1006-5, Shanghai Jingke Chemical Technology Co., Ltd., Shanghai, China) for 5-10 min, and washed under running water for $30 \mathrm{~s}$. Subsequently, the tissues were differentiated with $0.5 \%$ acetic acid solution for $1 \mathrm{~min}$, dehydrated with ethanol (95\%-100\%), cleared with xylene, mounted with neutral balsam and observed under a fluorescence microscope. The green-stained region in the mesenchyme was analyzed using a computer image analysis system (HPIAS-1000). Ten non-overlapping fields were selected from each slice under the microscope at high-power magnification (400×) (XSP-36, Shenzhen Boshida Optical Instrument Co., Ltd., Shenzhen, China). The collagen volume fraction (CVF) of each stained tissue in each field was calculated using the following method: eight fields were selected from each stained slice, and the area of stained tissue was measured; the ratio of the obtained area to the whole area was considered the proportion of collagen tissue in each field; and the boundary area of the blood vessels enriched with collagen was not included. The CVF was regarded as the mean value that was calculated automatically using Image-Pro Plus image analysis software (Media Cybernetics, MD, USA).

\section{Reverse Transcription-Quantitative Polymerase Chain Reaction (RT-qPCR)}

The total RNA of the left kidney from treated mice was extracted using a TRIzol extraction kit. Primers for miR-376b and Atg5 mRNA were designed and then synthetized by Takara Biotechnology Co., Ltd. (Dalian, Liaoning, China) (Table 1). The RNA was reversely transcribed to complementary DNA (cDNA) using a PrimeScript RT kit (RR036A, Takara Biotechnology Co., Ltd., Dalian, Liaoning, China). The RT system was 10 $\mu \mathrm{L}$, and the reaction was conducted according to the instructions. The reaction conditions consisted of three cycles of $37^{\circ} \mathrm{C}$ for $15 \mathrm{~min}$ (reverse transcription) and $85^{\circ} \mathrm{C}$ for $5 \mathrm{~s}$ (reverse transcriptase inactivation). The RT mixture was subjected to fluorescence quantitative PCR using a SYBR@ Premix Ex Taq ${ }^{\mathrm{TM}}$ II kit (RR820A, TaKaRa Biotechnology Co., Ltd., Dalian, Liaoning, China) according to the instructions. The reaction system, which consisted of a total volume of $50 \mu \mathrm{L}$, contained $25 \mu \mathrm{L}$ of SYBR® Premix Ex Taq ${ }^{\mathrm{TM}}$ II $(2 \times), 2 \mu \mathrm{L}$ of forward primer, $2 \mu \mathrm{L}$ of reverse primer, $1 \mu \mathrm{L}$ of ROX Reference Dye (50×), $4 \mu \mathrm{L}$ of DNA template and $16 \mu \mathrm{L}$ of double-distilled water $\left(\mathrm{ddH}_{2} \mathrm{O}\right)$. Real-time quantitative RT-PCR was performed using an ABI7500 qPCR instrument (model \# 7500, Applied Biosystems, Foster City, CA, USA). The reaction conditions were predenaturation for $30 \mathrm{~s}$ at $95^{\circ} \mathrm{C}$ followed by 40 cycles of denaturation for $5 \mathrm{~s}$ at $95^{\circ} \mathrm{C}$, annealing and extension for $30 \mathrm{~s}$ at $60^{\circ} \mathrm{C}$. Two micrograms of total RNA was used as the template. The relative transcriptional level of miR-376b was calculated based on the $2-{ }^{\Delta \Delta \mathrm{Ct}}$ method $(\Delta \Delta \mathrm{CT}=\Delta \mathrm{Ct}$ experiment group $-\Delta \mathrm{Ct}$ control group and $\Delta \mathrm{Ct}=$ $\mathrm{Ct}$ target gene $-\mathrm{Ct}_{\text {internal reference }}$ ) using U6 served as the internal reference. The relative transcriptional level of Atg5 mRNA was calculated based on the $2{ }^{-\Delta \Delta \mathrm{Ct}}$ method using glyceraldehyde-3-phosphate dehydrogenase (GAPDH) as the internal reference. The relative mRNA level of the target gene was set to the value of $2^{-\Delta \Delta \mathrm{Ct}}$. The experiment was conducted three times.

\section{Western Blot Analysis}

The total protein from the kidney tissue of the mice in each group was extracted using a Radio Immunoprecipitation Assay (RIPA) kit (R0010, Beijing Solarbio Life Sciences Co., Ltd., Beijing, China). The protein concentration was determined using a bicinchoninic acid (BCA) kit (G3522-1, GBCBIO Technologies Inc., Guangzhou, Guangdong, China). The protein was quantified based on different concentrations, isolated bypolyacrylamide gel electrophoresis and wet-transferred to a nitrocellulose membrane. The membrane was blocked with $5 \%$ bovine serum albumin (BSA) at room temperature for $1 \mathrm{~h}$ and incubated with the following antibodies (all purchased from Abcam Inc., Cambridge, UK) overnight at $4^{\circ} \mathrm{C}$ : primary rabbit polyclonal antibodies against Beclin-1 (1:1000 dilution, ab62557), light chain 3 (LC3)

Table 1. Primer sequences for RT-qPCR. Note: RT-qPCR, reverse transcription-quantitative polymerase chain reaction; miR-376b, microRNA376b; Atg5, autophagy-related gene 5; GAPDH; glyceraldehyde-3-phosphate dehydrogenase; F, forward; R, reverse

\begin{tabular}{lc}
\hline Gene & Primer sequence (5'-3') \\
\hline \multirow{2}{*}{ miR-376b } & F: CAGGAAGTTCCGCCCCTCTA \\
& R: AAGCAAGACTGGATCACGCA \\
U6 & F: TCTGTGGAACCCTCCACTCT \\
& R: GCTTAGGATGCTGCTCCCAT \\
\multirow{2}{*}{ Atg5 } & F: TTTGGGCCATCAACCGGAAA \\
& R: CATCTAGCGAGGAGGACACAC \\
GAPDH & F: AGCCTCGTCCCGTAGACAAA \\
& R: CAACAATCTCCACTTTGCCACT \\
\hline
\end{tabular}




\section{Kidney Blood Pressure Research}

Yang et al.: miR-376b Targeting Atg5 Modulates RIF in CKD

(1:2000, ab128052), B-cell lymphoma 2 (Bcl-2) (1:1000, ab59348), Bax (1:1000, ab32503), and caspase-3 (1:500, ab13847) and rabbit monoclonal antibody against GAPDH (1:1000, ab8245). Five 5-min washes with phosphate-buffered saline (PBS) were performed. A goat anti-rabbit immunoglobulin G (IgG) antibody (1:5000, Beijing Zhongshan Biotechnology Co., Ltd., Beijing, China) labeled with horse radish peroxidase (HRP) was added to the samples for incubation. The membrane and enhanced chemiluminescence (ELC) solution were allowed to interact for $1 \mathrm{~min}$. The liquid was soaked out with a preservative film cover. The X-ray film (36209ES01, Shanghai Qcbio Science \& Technology Co., Ltd., Shanghai, China) was exposed for observation. The gray values of the proteins were analyzed using ImageJ software, and the relative protein

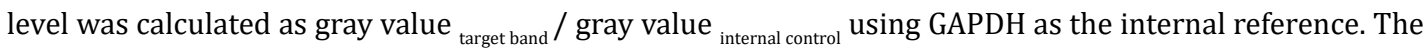
experiment was repeated three times.

\section{Isolation of Macrophages and Kidney Fibroblasts (KFBs)}

Thigh and shin bones from both hind limbs were collected, and the cartilaginous tissue on both ends was removed. The marrow cavity was washed thoroughly through the injection of complete culture medium using a syringe $(1 \mathrm{~mL})$. A single-cell suspension was obtained and centrifuged, and the supernatant was discarded. The suspension was treated with red blood cell lysis buffer (R1010, Beijing Solarbio Science \& Technology Co. Ltd., Beijing, China), and the reaction was terminated by complete medium. The supernatant was removed after centrifugation. The sample was cultured at $37^{\circ} \mathrm{C}$ with $3 \% \mathrm{O}_{2}, 5 \% \mathrm{CO}_{2}$ and $92 \% \mathrm{~N}_{2}$ for 8-12 $\mathrm{h}$, and the collected supernatant was centrifuged. After the supernatant was discarded, the cells were resuspended in high glucose-Dulbecco's Modified Eagle's Medium (H-DMEM) and low glucose-DMEM (L-DMEM) supplemented with macrophage colony-stimulating factor (M-CSF, $60 \mathrm{ng} / \mathrm{mL}$ ). After culturing for 6-7 days, the obtained macrophages were washed with PBS and treated with trypsin. The digestion was terminated with L-DMEM. Centrifugation was performed again, and the supernatant was discarded. Morphological identification was conducted under an optical microscope (SG-51, Shanghai Instrument Factory, Shanghai, China). Next, $300 \mu \mathrm{L}$ of DMEM containing serum was added, and the total number of macrophages was counted using a Cell Counter. The density was adjusted to a density of $1 \times 10^{6} \mathrm{cells} / \mathrm{mL}$. Kidney tissues were collected under sterile conditions. The fat was separated, and the capsule was removed and washed with PBS. The separated cortex and medulla were cut into blocks of $1 \mathrm{~mm}^{3}$, washed twice with PBS and centrifuged at $1500 \mathrm{rpm}$ for $5 \mathrm{~min}$, and the supernatant was adsorbed. The specimens were detached with five to six volumes of $0.25 \%$ trypsin at $37^{\circ} \mathrm{C}$ for $15-20 \mathrm{~min}$. The digestion was terminated with Roswell Park Memorial Institute (RPMI) 1640 culture medium supplemented with 30\% bovine serum. The cell suspension obtained with the digestion solution was filtered through 200-mesh nylon net and centrifuged at $1000 \mathrm{rpm}$ for $5 \mathrm{~min}$. After the supernatant was removed, culture medium was added to the precipitate to create a cell suspension. The density of the cells was adjusted to $1.0 \times 10^{6}$ cells $/ \mathrm{mL}$. The cells were seeded in a culture bottle and cultured at $37^{\circ} \mathrm{C}$ in $5 \% \mathrm{CO}_{2}$ for $24 \mathrm{~h}$. The medium was replaced every three days. Morphological identification of the macrophages and KFBs of the primary generation was performed under a phase-contrast microscope (HD-2000A, Shenzhen Boshida Optical Instrument Co., Ltd., Shenzhen, China).

\section{Monodansylcadaverine (MDC) Staining}

Autophagy inhibitor 3-MA (Sigma-Aldrich Chemical Company, St Louis, MO, USA) was diluted using sterile PBS. The final concentration of stock solution was adjusted to $40 \mathrm{mM}$, and the stock solution was sub-packed at $20^{\circ} \mathrm{C}$ for further usage. MDC powder (Sigma-Aldrich Chemical Company, St Louis, MO, USA) was dissolved in dimethyl sulfoxide (DMSO) to obtain a final concentration of $0.1 \mathrm{M}$ and then stored at $-20^{\circ} \mathrm{C}$. The macrophages were seeded into six-well plates, treated with 3-MA and cultured in brand-new culture medium containing $50 \mu \mathrm{m}$ of $\mathrm{MDC}$ at $37^{\circ} \mathrm{C}$ in $5 \% \mathrm{CO}_{2}$ for $10 \mathrm{~min}$. The solutions were centrifuged at 1000 rpm and resuspended for $10 \mathrm{~min}$. The cells were applied to slide glass with a cover glass, observed under an inverted fluorescence microscope OLYMPUS IX71 (Olympus Corp., Tokyo, Japan), activated by ultraviolet light, and imaged.

Detection of Autophagy Level and Related-Protein Colocalization

Macrophages collected from the mice after treatment for $24 \mathrm{~h}$ were placed on a 48-well culture dish with a cover slip and incubated at $37^{\circ} \mathrm{C}$ with $5 \% \mathrm{CO}_{2}$. The cells were fixed with frozen $4 \%$ paraformaldehyde 


\section{Kidney Blood Pressure Research}

Yang et al.: miR-376b Targeting Atg5 Modulates RIF in CKD

for $15 \mathrm{~min}$, washed with PBS, and treated with $0.1 \%$ Triton X-100 for $15 \mathrm{~min}$. Primary and secondary antibodies diluted with culture medium were added to each well $(250 \mu \mathrm{L} /$ well). The plates were then incubated at $37^{\circ} \mathrm{C}$ in $5 \% \mathrm{CO}_{2}$ and then washed with PBS. The cells were then stained with 4',6-diamidino2-phenylindole (DAPI, $0.3 \mu \mathrm{g} / \mathrm{mL}$ ) for $20 \mathrm{~min}$ in the dark. A drop of anti-fluorescent quenching mounting medium was dripped on the slide glass over which cells had settled. A laser scanning confocal microscope (LSCM) (Keyence Cor., Osaka, Japan) was used for observation. The excitation wavelength, transmission wavelength and scanning intensity of fluorescein isothiocyanate (FITC) were set to $488 \mathrm{~nm}, 500-540 \mathrm{~nm}$ and 23, respectively; those of Cy3 were set to $543 \mathrm{~nm}, 560-670 \mathrm{~nm}$ and 50; and those of DAPI were set to $405 \mathrm{~nm}, 410-460 \mathrm{~nm}$ and 50. The resolution was 1024:60 n.

\section{Detection of Reactive Oxygen Species (ROS)}

Macrophages were collected $\left(1 \times 10^{6}\right.$ cells $\left./ \mathrm{mL}\right)$, washed once with cold PBS and incubated with $10 \mu \mathrm{M}$ $2^{\prime}, 7^{\prime}$-dichlorodihydrofluorescein diacetate (DCFH-DA) at $37^{\circ} \mathrm{C}$ for $30 \mathrm{~min}$ in the dark. The reclaimed cells were resuspended with $1 \mathrm{~mL}$ of PBS and then added to a 96-well plate. Five parallel wells were used for each concentration. A fluorescence microplate reader (Molecular Devices, Silicon Valley, CA, USA) was utilized for the analysis.

\section{3-(4, 5-Dimethyl-2-Thiazolyl)-2, 5-Diphenyl-2-H-Tetrazolium Bromide (MTT) Assay}

Once the cell confluence reached approximately $80 \%$, KFBs were seeded into a 96-well plate at a density of $2 \times 10^{3}$ cells/well. Each well was supplemented with $100 \mu \mathrm{L}$ of culture medium, and the plate was placed in an incubator at $37^{\circ} \mathrm{C}$ with $5 \% \mathrm{CO}_{2}$ for $24,48,72$ or $96 \mathrm{~h}$. Then, $20 \mu \mathrm{L}$ of MTT solution (5 g/L) was added to each well, and the plate was cultured for $4 \mathrm{~h}$. The supernatant was discarded, and $150 \mu \mathrm{L}$ of DMSO was added to each well. The plate was shaken for $10 \mathrm{~min}$, and a microplate reader was used to determine the absorbance (A) at $490 \mathrm{~nm}$ as the viability of the cells, based on which the cell growth curve was drawn.

\section{5-Ethynyl-2'-Deoxyuridine (EdU) Assay}

Once the cell confluence reached approximately $80 \%$, the KFBs in each group were inoculated into a 96-well plate at a density of $2 \times 10^{3} /$ well. The cells in each well were then cultured with $100 \mu \mathrm{L}$ of culture medium in an incubator at $37^{\circ} \mathrm{C}$ with $5 \% \mathrm{CO}_{2}$ and then stained with $100 \mu \mathrm{L}$ of EdU (50 $\left.\mu \mathrm{M}\right)$ for $48 \mathrm{~h}$. Immunofluorescence staining was conducted using EdU reagent kits (C10310, Guangzhou RiboBio Co., Ltd., Guangzhou, Guangdong China) based on the instructions, and images were then acquired using an Olympus microscope (BX53, Olympus Optical Co., Ltd, Tokyo, Japan).

\section{Flow Cytometry for Determining the Macrophage Phagocytosis Rate}

Eighty microliters of fluorescence microspheres was incubated with $8 \mathrm{~mL}$ of $1 \% \mathrm{BSA}$ at $37^{\circ} \mathrm{C}$ for $30 \mathrm{~min}$. The specimens were ultrasonically processed for $5 \mathrm{~min}$ and transferred to six-well plates, the supernatant was absorbed, and the specimens were washed with PBS. Then, $1 \mathrm{~mL}$ of culture medium was added to each well, and the fluorescence microspheres $(1 \mathrm{~mL})$ were adjusted with $1 \%$ BSA. The macrophages and microspheres were incubated at $37^{\circ} \mathrm{C}$ for $50 \mathrm{~min}$ in the dark. The supernatant was removed, and the mixture was washed twice with cold PBS $(2 \mathrm{~mL})$. Sheath fluid $(500 \mu \mathrm{L})$ was mixed into the wells, and the floating cells were transferred to the flow cytometry tube. A flow cytometer (6HT, Wuhan Cellwar Biotechnology, Co., Ltd., Wuhan, Hubei, China) was used for the analysis.

\section{Flow Cytometry for the Cell Apoptosis of KFBs}

Cell apoptosis was examined by Annexin V-FITC/propidium iodide (PI) double-staining. The cells were treated using the same protocol used for the cell cycle analysis. After $48 \mathrm{~h}$ of incubation at $37^{\circ} \mathrm{C}$ in $5 \% \mathrm{CO}_{2}$, the collected cells were washed twice with PBS, centrifuged and resuspended in $200 \mu \mathrm{L}$ of binding buffer solution. Then, $10 \mu \mathrm{L}$ of Annexin V-FITC and $5 \mu \mathrm{L}$ of PI were added, and the mixture was mixed gently in the dark for 15 min to allow the reaction to occur. Three hundred microliters of binding buffer solution was added, and cell apoptosis was analyzed by the detection of FITC and PI fluorescence obtained after activation of the bandpass at $525 \mathrm{~nm}$ and $620 \mathrm{~nm}$ using a wavelength of $488 \mathrm{~nm}$ with a flow cytometer (6HT, Wuhan Cellwar Biotechnology, Co., Ltd., Wuhan, Hubei, China). 


\section{Kidney Blood Pressure Research}

\section{Statistical Analysis}

The data were analyzed using SPSS 21.0 software (IBM Corp. Armonk, NY, USA). The measurement data are presented as the means \pm standard deviations. The differences between two groups were analyzed using a $t$-test, and the data among multiple groups were statistically analyzed using one-way analysis of variance (ANOVA). A $p<0.05$ indicated statistical significance.

\section{Results}

\section{miR-376b Directly Targets Atg5}

First, a biological prediction website was used to confirm the targeting relationship between miR-376b and Atg5. In particular, the results identified specific binding sites in the sequences of the Atg5 mRNA 3'UTR and miR-376b, which suggested that Atg5 was a target gene of miR-376b (Fig. 1A). The results from a dual-luciferase reporter assay further verified that Atg5 was a target of miR-376b (Fig. 1B). Compared with the NC mimic group, the luciferase activity of wild-type miR-376b/Atg5 (WT-miR-376b/Atg5) was weakened in the miR-376b mimic group $(p<0.05)$. However, no significant difference in luciferase activity was obtained with the mutant 3'UTR ( $p>0.05)$. These results revealed that miR-376b can specifically bind to the Atg5 gene.

\section{Deregulated miR-376b Suppresses RIF in Mice with CKD}

$\mathrm{HE}$ and Masson staining were then performed to observe and evaluate the pathological changes. HE staining (Fig. 2A) showed that the control group exhibited a normal glomerulus (blue arrows), with no broadened interstitial region or medullary region. Compared with the control group, atrophied glomeruli, more mesangial cells and a broadened interstitial region were detected in the other groups (blue arrows). No significant difference was observed between the blank and NC groups. In contrast, the miR-376b mimic and Atg5 shRNA groups exhibited serious atrophy compared to the blank and NC groups, respectively, and it was difficult to distinguish the interstitial region from the medullary region in these experimental groups. The mice in the miR-376b inhibitor group exhibited atrophied glomeruli, decreased numbers of mesangial cells, and a broadened interstitial region compared with the blank and $\mathrm{NC}$ groups. The pathological conditions did not show significant differences among the blank, NC and miR-376b inhibitor + Atg5 shRNA groups. According to the Masson staining results (Fig. $2 \mathrm{~B}, \mathrm{C}$ ), fibrillar collagen deposition (blue part) on the renal tubular basement membrane was not observed in the control group. Compared with the control group $(3.20 \% \pm 0.90 \%)$, an increase in fibrillar collagen deposition was observed in the other groups, and this increase was accompanied by higher CVF values $(p<0.05)$. No significant difference was observed between the blank group $(19.81 \% \pm 1.20 \%)$ and the NC group $(20.32 \% \pm 1.70 \%)(p>0.05)$. In the mice treated with miR-376b mimic or Atg5 shRNA, a marked number of renal tubules showed atrophy,

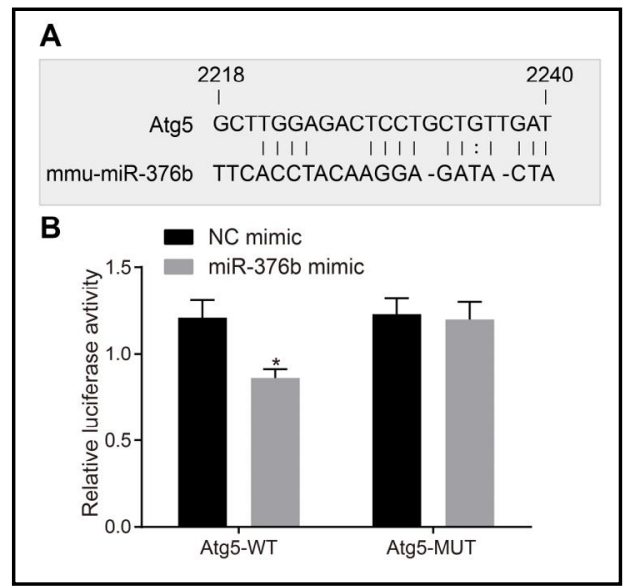

Fig. 1. Atg5 is a target gene of miR-376b. A, Binding relationship predicted by a biological prediction website (https://cm.jefferson. edu/rna22/Interactive/). B, An analysis of luciferase activity indicates that Atg5 is a target of miR-376b. The measurement data are presented as the means \pm standard deviations, and comparisons among multiple groups were performed with one-way ANOVA. The experiment was independently repeated three times. ${ }^{*}, \mathrm{p}<0.05$ vs. the NC mimic group; Atg5, autophagy-related gene 5; miR-376b; microRNA-376b; ANOVA, analysis of variance. 


\section{Kidney \\ Blood Pressure Research}

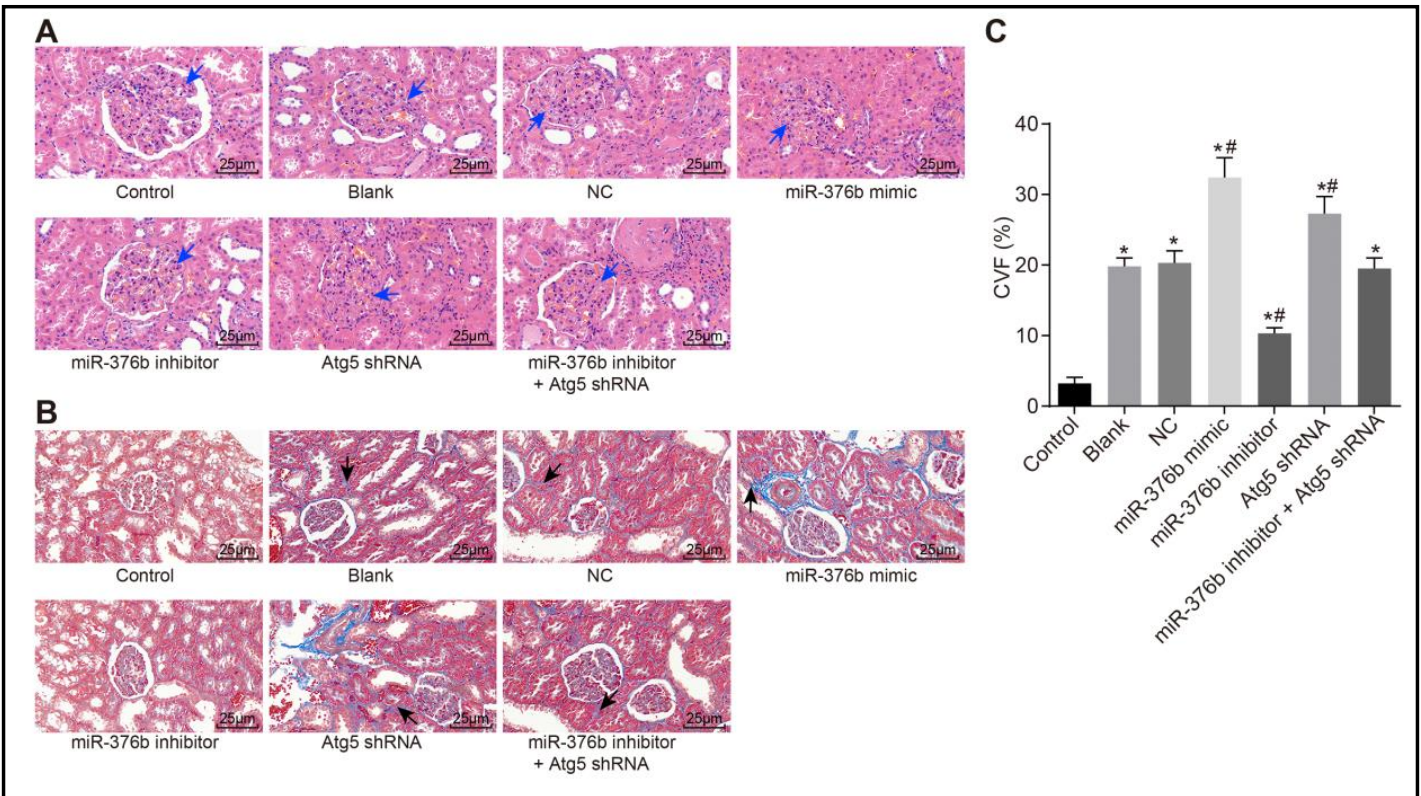

Fig. 2. Deregulated miR-376b suppresses renal interstitial fibrosis in mice with chronic kidney disease. A, HE staining $(\times 400)$ of mice treated with miR-376b mimic or Atg5 shRNA shows seriously atrophied glomeruli (blue arrows) and the difficulty in distinguish the interstitial region from the medullary region. $\mathrm{B}$, Masson staining $(\times 400)$ of mice treated with miR-376b mimic or Atg5 shRNA shows a high number of atrophied renal tubules and obviously increased fibrillar collagen deposition (black arrows). C, The CVF value is lower in mice treated with miR-376b inhibitor alone. The measurement data are presented as the means \pm standard deviations, and comparisons among multiple groups were performed with one-way ANOVA; the experiment was repeated three times; ${ }^{*}, \mathrm{p}<0.05$ vs. the control group; \#, $\mathrm{p}<0.05$ vs. the blank and NC groups; Atg5, autophagy-related gene 5; miR-376b; microRNA-376b; ANOVA, analysis of variance; $\mathrm{HE}$, hematoxylin-eosin; CVF, collagen volume fraction; $\mathrm{NC}$, negative control.

increased mounting fibrillar collagen deposition (blue part) was obviously observed in the renal interstitium, and the CVF values were increased to $32.40 \% \pm 2.81 \%$ and $27.30 \% \pm$ $2.42 \%$, respectively $(p<0.05)$. The mice in the miR-376b inhibitor group exhibited less fibrillar collagen deposition on the renal tubular basement membrane and a lower CVF value $(10.31 \% \pm 0.81 \%)(p<0.05)$ in comparison with the blank and NC groups $(p>0.05)$, and similar findings were obtained for the miR-376b inhibitor + Atg5 shRNA group $119.50 \% \pm$ $1.52 \%$ ). These findings make it clear that deregulated miR-376b suppresses RIF in mice with CKD.

\section{Successful Identification of Macrophages and KFBs}

The isolated cells were then subjected to morphological identification under a phase contrast microscope. As shown in Fig. 3A, most macrophages tended to be roundish in shape, whereas others exhibited a radial shape with pseudopods and protuberances. Prior to adherence, primary KFBs were uniformly spherical and existed as single cells with a clear boundary, and the nucleus was surrounded by a halo (Fig. 3B). Therefore, we could reliably identify macrophages and KFBs for the subsequent experiments. 


\section{Kidney Blood Pressure Research}

Kidney Blood Press Res 2018;43:1749-1764

\begin{tabular}{|l|l|l|l|l}
\hline DOI: 10.1159/000495394 & (c) 2018 The Author(s). Published by S. Karger AG, Base
\end{tabular}

Published online: 23 November 2018 www.karger.com/kbr

1757

Fig. 3. Identification of isolated cells. A, Most macrophages tend to be roundish in shape, whereas others exhibit a radial shape with pseudopods and protuberances ( $x$ 100). B, Before adherence, the primary KFBs are uniformly spherical and exist as single cells, with clear boundaries, and the nucleus is surrounded by a halo $(x$ Yang et al.: miR-376b Targeting Atg5 Modulates RIF in CKD

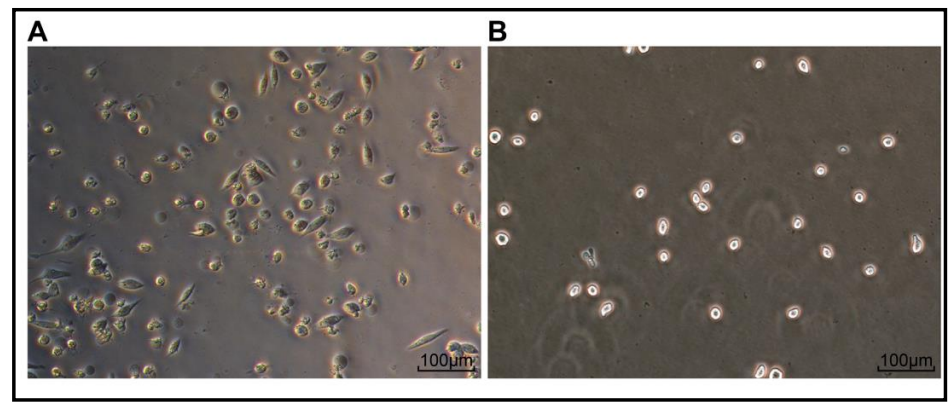
100); KFBs, kidney fibroblasts.

\section{Deregulated miR-376b Promotes Autophagy of Macrophages}

Subsequently, MDC staining and LSCM were performed to evaluate the level of macrophage autophagy. The MDC staining results (Fig. 4A) demonstrated that in contrast to the control group, mitochondrial autophagy was suppressed in the other groups, which exhibited markedly fewer autophagic vacuoles $(p<0.05)$. No significant difference was observed between the blank and NC groups ( $p>0.05)$, whereas in comparison to both of these groups, the level of autophagy and the number of autophagic vacuoles were decreased in the mice treated with miR-376b mimic or Atg5 shRNA $(p<0.05)$. The opposite changes tended to be observed in the miR-376b inhibitor group $(p<0.05)$. The above indicators did not differ significantly in the miR-376b inhibitor + Atg5 shRNA group $(p>0.05)$. These results indicated that miR-376b overexpression remarkably impairs the formation of autophagic vacuoles.

The LSCM results are presented in Fig. 4B. Compared with the control group, the number of autophagosomes was decreased in the other groups $(p<0.05)$. No significant difference was observed between the blank and NC groups $(p>0.05)$. In comparison to both of these groups, notably fewer autophagosomes were found in the miR-376b mimic and Atg5 shRNA groups, a higher number of autophagosomes were observed in the miR-376b inhibitor group $(p<0.05)$. However, the number of autophagosomes did not show a significant difference between the miR-376b inhibitor + Atg5 shRNA group and the control group $(p>0.05)$. Based on the confirmation of mitochondrial autophagy, it can be concluded that miR-376b overexpression inhibits the formation of autophagosomes.

The results of the phagocytosis analysis are illustrated in Fig. 4C. Compared with the control group $(65.31 \% \pm 5.60 \%)$, mitochondrial phagocytosis in macrophages was reduced in the other groups $(p<0.05)$. No significant difference in the autophagy rate was observed between the blank group $(43.72 \% \pm 3.41 \%)$ and the NC group $(42.6 \% \pm 3.20 \%)(p>0.05)$, and in comparison to both of these groups, phagocytosis was decreased in the mice treated with miR-376b mimic $(12.30 \% \pm 2.11 \%)$ or Atg5 shRNA $(7.82 \% \pm 1.60 \%)$ but increased in those treated with miR-376b inhibitor $(54.61 \% \pm 4.21 \%)(p<0.05)$. However, no significant difference in mitochondrial phagocytosis in macrophages was observed between the miR$376 \mathrm{~b}$ inhibitor + Atg5 shRNA group $(43.22 \% \pm 3.53 \%)$ and the blank and NC groups $(p>$ $0.05)$. These results showed that deregulated miR-376b promotes macrophage autophagy.

\section{Deregulated miR-376b Promotes ROS Production}

A fluorescence microplate reader was then adopted to determine the level of ROS in mitochondria (Fig. 5). Compared with the control group $(1.55 \% \pm 0.10 \%)$, a lower level of ROS was detected in the other groups $(p<0.05)$, and no significant difference was observed between the blank group $(0.93 \% \pm 0.11 \%)$ and the NC group $(0.94 \% \pm 0.10 \%)(p>0.05)$. Compared with the blank and NC groups, decreased ROS levels were found in the mice treated with miR-376b mimic $(0.33 \% \pm 0.05 \%)$ or Atg5 shRNA $(0.20 \% \pm 0.04 \%)$, whereas higher ROS levels were found in the mice treated with miR-376b inhibitor $(1.21 \% \pm 0.12 \%)(p<$ 0.05). No significant difference was observed between the miR-376b inhibitor + Atg5 shRNA 


\section{Kidney \\ Bloód Pressure \\ Research}

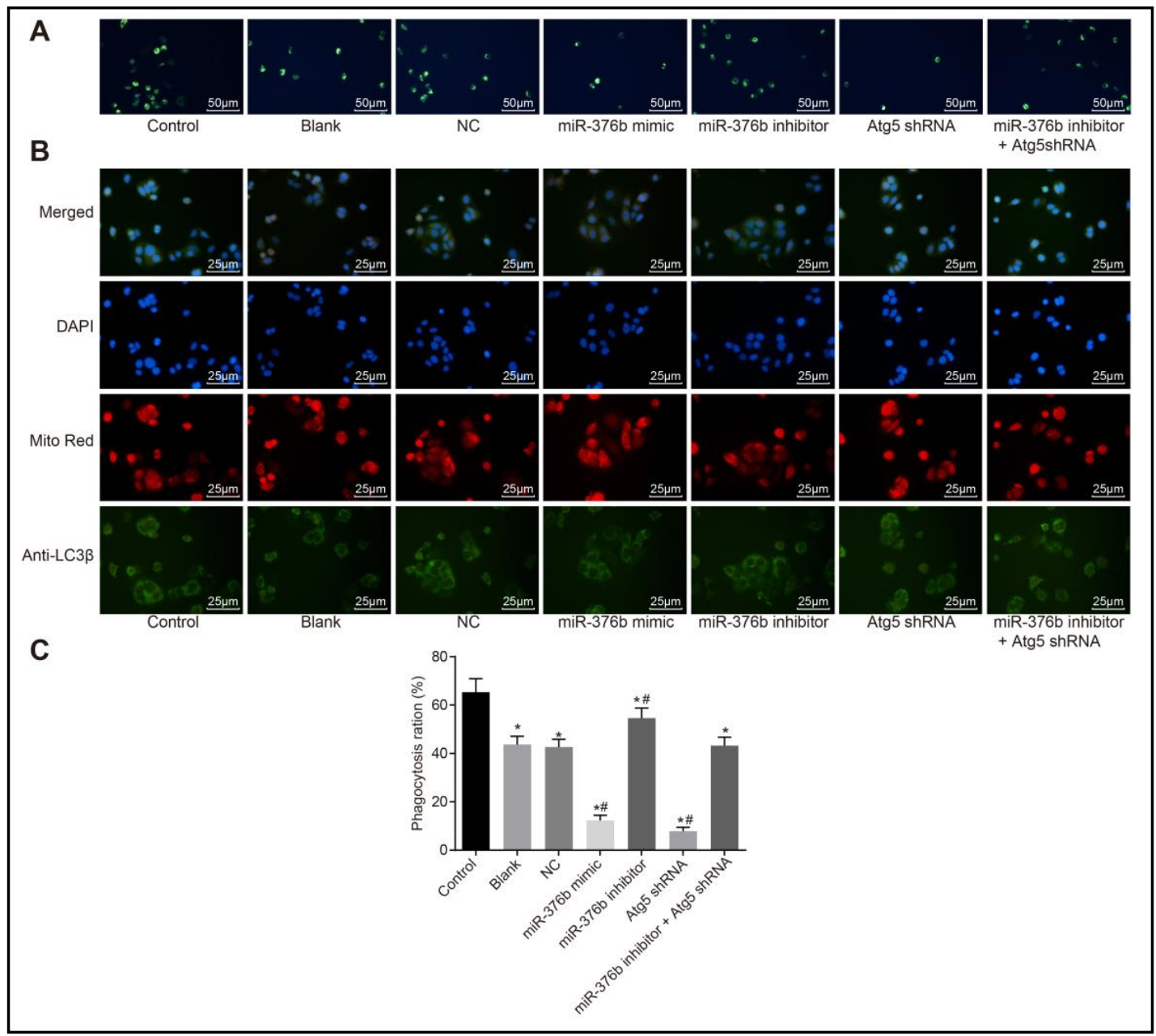

Fig. 4. Deregulated miR-376b promotes autophagy of macrophages. A, Level of autophagy and number of autophagic vacuoles in mice treated with miR-376b mimic or Atg5 shRNA detected by MDC staining $(x$ 200). B, Based on the confirmation of mitochondrial autophagy, miR-376b suppresses the formation of the autophagosome, as observed under a LSCM ( $\times 400)$. C, Phagocytosis is markedly decreased in mice treated with miR-376b mimic or Atg5 shRNA. The measurement data are presented as the means \pm standard deviations, and comparisons among multiple groups were performed with one-way ANOVA. The experiment was independently repeated three times. ${ }^{*}, \mathrm{p}<0.05$ vs. the control group; \#, $\mathrm{p}<0.05$ vs. the blank and NC groups; Atg5, autophagy-related gene 5; miR-376b; microRNA-376b; ANOVA, analysis of variance; NC, negative control; MDC, monodansylcadaverine; LSCM, laser scanning confocal microscope.

group $(0.94 \% \pm 0.09 \%)$ and the blank and NC groups $(p>0.05)$. These findings provide evidence showing that deregulated miR-376b promotes ROS production.

\section{Downregulation of miR-376b Promotes Atg5 Expression}

RT-qPCR and western blot analyses were conducted to detect certain mRNA and protein levels, respectively. RT-qPCR and western blot analyses of samples from mice treated with different plasmids showed that compared with the control group, the other groups exhibited significantly elevated expression of miR-376b and $\mathrm{Bcl}-2$ and decreased expression of Atg5 mRNA, Beclin-1, LC3 II/I, Bax and caspase-3 ( $p<0.05$ ) (Fig. 6A-C). No significant difference was observed between the blank and NC groups $(p>0.05)$. The RT-qPCR analysis revealed that in comparison to the blank and NC groups, the miR-376b mimic group exhibited notably increased miR-376b expression and decreased Atg5 expression, whereas the opposite 


\section{Kidney Blood Pressure Research}

findings were obtained in the miR-376b inhibitor group $(p<0.05)$. Compared with the miR$376 \mathrm{~b}$ inhibitor group, the miR-376b mimic group showed increased miR-376b expression $(p<0.05)$. Nevertheless, the expression of miR-376b and Atg5 did not show any difference between the Atg5 shRNA group and the miR-376b inhibitor + Atg5 shRNA group $(p>0.05)$. Reduced Atg5 and miR-376b expressions were found in the Atg5 shRNA and miR-376b inhibitor + Atg5 shRNA groups, respectively $(p<0.05)$. The above results indicated that miR-376b silencing might upregulate Atg5 in CKD.

The western blot analysis revealed that in comparison to the blank and NC groups, the miR-376b mimic and Atg5 shRNA groups exhibited markedly decreased levels of Beclin-1, LC3 II/I, Bax and caspase-3 and notably increased Bcl-2 expression ( $p<$ $0.05)$. In addition, the miR-376b inhibitor group exhibited an opposite effect $(p<0.05)$, and no significant change was detected in the miR-376b inhibitor + Atg5 shRNA group $(p>0.05)$. These findings indicated that miR-376b inhibits Atg5 expression. Taken together, the above-described results demonstrate that miR-376b might promote the protein level of $\mathrm{Bcl}-2$ and decrease the protein levels of Beclin-1, LC3 II/I, Bax and caspase- 3 by inhibiting Atg5, which indicates that miR-376b might be responsible for cell autophagy in CKD.

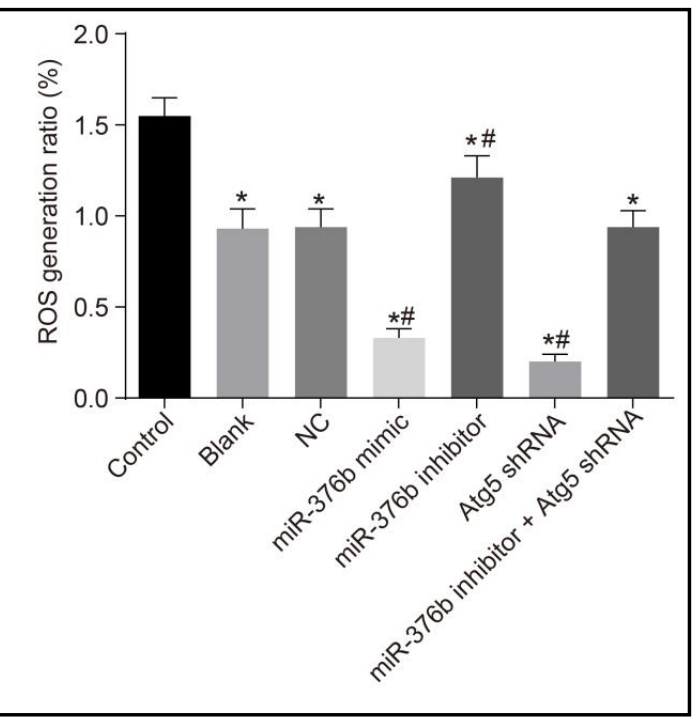

Fig. 5. Deregulated miR-376b promotes ROS production. *, $\mathrm{p}<0.05$ vs. the control group; \#, $\mathrm{p}<0.05$ vs. the blank and NC groups. The measurement data are presented as the means \pm standard deviations, and comparisons among multiple groups were performed with one-way ANOVA. The experiment was independently repeated three times; miR-376b; microRNA-376b; ANOVA, analysis of variance; NC, negative control; ROS, reactive oxygen species.

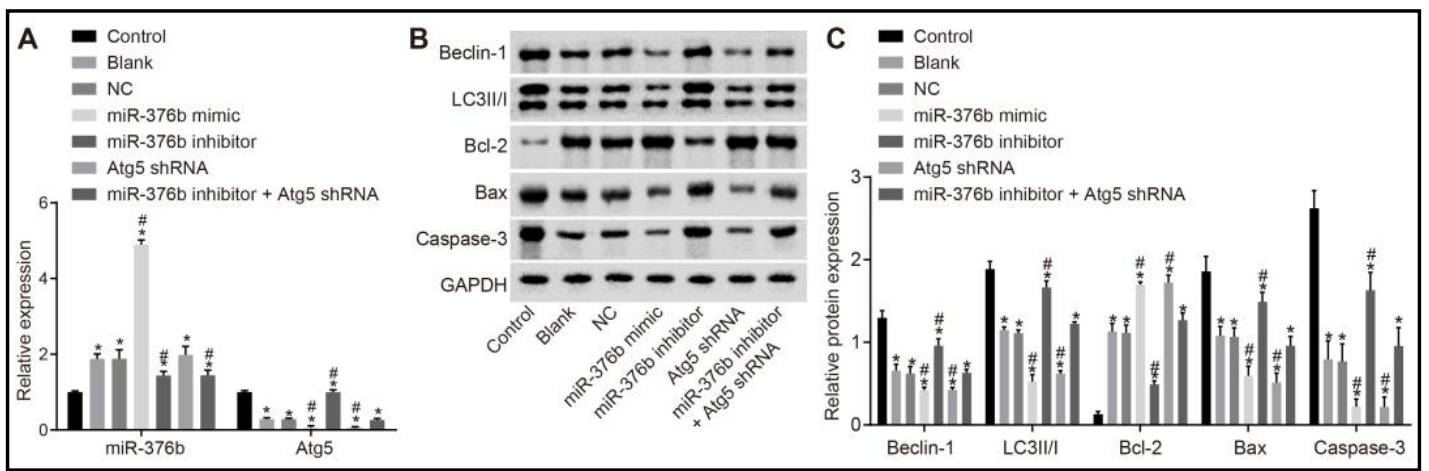

Fig. 6. Downregulation of miR-376b promotes Atg 5 expression and reduces cell autophagy in CKD. A, mRNA level of Atg5 in the mice treated with miR-376b mimic or Atg5 shRNA, as determined by RT-qPCR. B, Gray values of Beclin-1, LC3 II/I, Bcl-2, Bax, caspase-3 and GAPDH protein bands, as determined by western blot analysis. C, Protein levels of Beclin-1, LC3 II/I, Bax, Bcl-2 and caspase-3 in the mice treated with miR$376 \mathrm{~b}$ mimic or Atg5 shRNA. The measurement data are presented as the means \pm standard deviations, and comparisons among multiple groups were performed with one-way ANOVA. The experiment was independently repeated three times. *, p<0.05 vs. the control group; \#, p<0.05 vs. the blank and NC groups; Atg5, autophagy-related gene 5; miR-376b; microRNA-376b; ANOVA, analysis of variance; NC, negative control; RT-qPCR, reverse transcription-quantitative polymerase chain reaction; CKD, chronic kidney disease; Bax, Bcl-2-associated X protein; Bcl-2, B-cell lymphoma 2; GAPDH, glyceraldehyde phosphate dehydrogenase; LC3, light chain 3. 


\section{Kidney Blood Pressure Research}

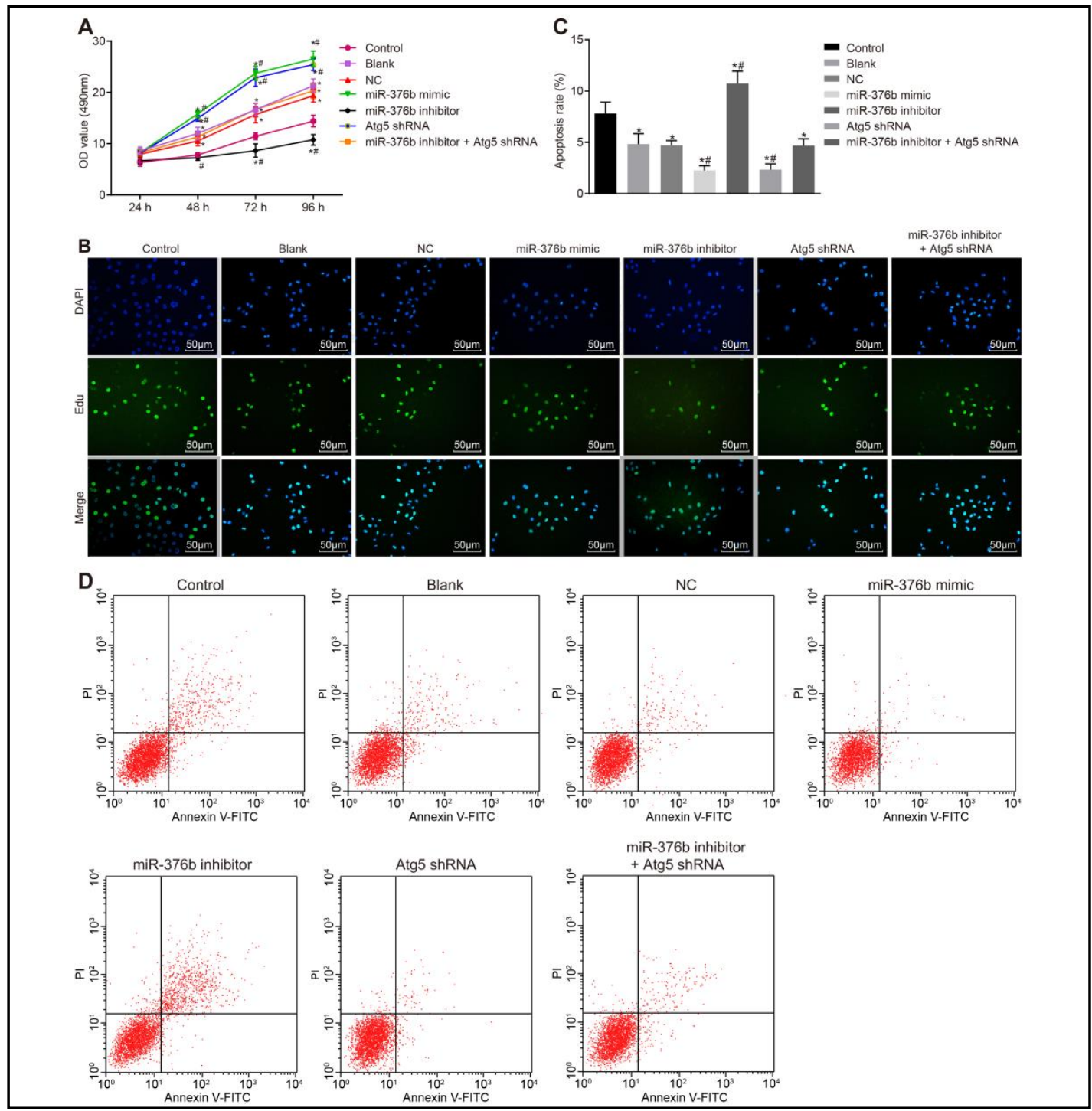

Fig. 7. Deregulated miR-376b inhibits the proliferation and promotes the apoptosis of KFBs. A, Proliferative ability of KFBs in mice treated with miR-376b mimic or Atg5 shRNA, as determined by MTT assay. B, Images of the proliferative ability of each group, as detected by EdU assay $(\times 200)$. C, Proliferative ability of KFBs in mice treated with miR-376b mimic or Atg5 shRNA. D, Apoptosis of KFBs in mice treated with miR-376b mimic or Atg5 shRNA, as detected by flow cytometry. ${ }^{*}, \mathrm{p}<0.05$ vs. the control group; \#, $<<0.05$ vs. the blank and NC groups. The measurement data are presented as the means \pm standard deviations, and comparisons among multiple groups were performed with one-way ANOVA. The experiment was independently repeated three times; Atg5, autophagy-related gene 5; miR-376b; microRNA-376b; ANOVA, analysis of variance; NC, negative control; KFBs, kidney fibroblasts; MTT, 3-(4,5-dimethylthiazol-2-yl)-2,5-diphenyltetrazolium bromide; EdU, 5-ethynyl-2'-deoxyuridine.

\section{Downregulated miR-376b or Upregulated Atg5 Inhibits Proliferation and Promotes Apoptosis of KFBS}

We assessed the proliferative ability of KFBs through MTT and EdU assays. The results revealed that compared with normal mice, the mice in the blank, NC, miR-376b mimic, Atg5 shRNA and miR-376b inhibitor + Atg5 shRNA groups exhibited an enhanced proliferative ability, whereas those in the miR-376b inhibitor group exhibited the opposite results $(p<$ 0.05 ) (Fig. 7A). No significant difference was observed between the blank and NC groups ( $p$ 


\section{Kidney Blood Pressure Research}

Kidney Blood Press Res 2018;43:1749-1764

\begin{tabular}{l|l}
\hline DOI: $10.1159 / 000495394$ & (c) 2018 The Author(s). Published by S. Karger AG, Basel
\end{tabular}

Published online: 23 November 2018 www.karger.com/kb

$>0.05)$. In comparison to the blank and NC groups, accelerated proliferation was detected in the mice treated with miR-376b mimic and Atg5 shRNA, whereas decreased proliferation was observed in the mice treated with miR-376b inhibitor $(p<0.05)$. The proliferation ability did not differ significantly among the blank, NC and miR-376b inhibitor + Atg5 shRNA groups $(p>0.05)$. Taken together, these results showed that downregulated miR-376b inhibits the proliferation of KFBs.

A flow cytometry analysis was conducted to detect the apoptotic ability of KFBs (Fig. 7B C). In comparison with the control group $(7.82 \% \pm 1.10 \%)$, the apoptosis rate was decreased in the blank group ( $4.83 \% \pm 1.02 \%)$, NC group $(4.72 \% \pm 0.45 \%)$, miR-376b mimic group $(2.27 \% \pm 0.45 \%), \operatorname{Atg} 5$ shRNA group $(2.34 \% \pm 0.57 \%)$, and miR-376b inhibitor + Atg5 shRNA group $(4.69 \% \pm 0.65 \%)$ but elevated in the miR-376b inhibitor group $(10.74 \% \pm 1.21 \%)$ (all $p<0.05)$. The apoptosis rate of the mice in the blank and NC groups exhibited no obvious difference ( $p>0.05)$. In contrast to the blank and NC groups, the miR-376b mimic and Atg5 shRNA groups presented reduced apoptotic rates $(p<0.05)$, whereas an enhanced rate was found in the miR-376b group $(p<0.05)$. The apoptosis rate in the miR-376b inhibitor + Atg5 shRNA group was not markedly different from that found in the blank and NC groups $(p>0.05)$. All these findings provide evidence showing that the apoptosis of KFBs could be enhanced by the downregulation of miR-376b.

\section{Discussion}

The kidney is a pivotal organ in the control of blood pressure, erythrocyte production, metabolic waste removal, and body fluid balance, which are all crucial for normal body function [24]. Nevertheless, statistics published by the Global Burden of Disease Study 2013 Collaborators have reported that the incidence of CKD increased by 48\% from 1990 to 2013, with an annual growth rate of approximately $2.1 \%$, and the situation might be aggravated by population aging [25]. Herein, we discuss the possible mechanisms that favor CKD and found that downregulated miR-376b negatively targets Atg5 to promote macrophage autophagy and inhibit RIF, which might provide a solution for fighting CKD.

A significant finding of our study is that Atg5 is a direct target of miR-376b, as demonstrated by the identification of specific binding sites in the sequences of the Atg5 gene and miR-376b. miRNAs exert their effects on translation by binding to the 3'UTR of their target genes in animals [26]. The identified targeting relationship was further shown to be negative because upregulated miR-376b and downregulated Atg5 were observed in the kidney tissues of mice with CKD. In fact, poorly expressed miRNAs are likely to cause cellular dysfunction, leading to the development of some diseases [27]. As reviewed by Lorenzen et al., miRNAs are downregulated in a diseased kidney and have been associated with kidney fibrosis as well as kidney dysfunction [28]. The latter finding is in line with our results, which showed that the mice in the miR-376b inhibitor group exhibited attenuated RIF compared with those treated with miR-376b mimic and Atg5 shRNA. RIF, the last pathway in the progression of CKD to end-stage renal disease, might result in a failed wound-healing response and abnormal tissue remodeling $[29,30]$. Moreover, macrophage autophagy tended to be promoted by miR-376b deregulation. Autophagy, which is characterized by the formation of autophagosomes, is related to the pathogenesis of some diseases, whereas the inhibition of autophagy might lead to cell apoptosis [30]. Macrophage recruitment and the inhibition of interstitial infiltration could alleviate renal fibrosis [31]. Autophagy upregulation could protect against kidney cell injury caused by oxidative stress and reduce the accumulation of collagen I, thus attenuating ischemic injury, suppressing renal fibrosis, and delaying AKI progression to CKD [32]. Li et al. found that Atg5 deficiency increases interstitial fibrosis, whereas the Atg5-mediated induction of autophagy is beneficial for protection against renal fibrosis [21]. Consistent with these results, the formation of autophagosomes was remarkably impaired in the miR-376b mimic and Atg5 shRNA groups in our study. Similarly, Wang et al. found that 


\section{Kidney \\ Blood Pressure Research}

autophagy mediated by Atg5 can create favorable conditions for improvements in ischemia injury in a rat model [19]. Taken together, the evidence shows that the repression of miR$376 \mathrm{~b}$ might attenuate RIF via the autophagy of macrophages by negatively targeting Atg5 in mice with CKD.

Another finding of the current study was that miR$376 \mathrm{~b}$ deregulation weakened the proliferative ability and enhanced theapoptosis potential of KFBs, as indicated by higher levels of ROS, Beclin-1, LC3 II/I, Bax and caspase- 3 and lower levels of CVF and Bcl-2. miRNAs are involved in various biological processes such as proliferation and apoptosis [27]. A group of Japanese researchers conducted experiments on mice with acute kidney injury and found that in proximal tubule-specific Atg5-knockout mice, autophagy protects the kidney from further impairment, probably through an increase in the production of ROS in the mitochondria, which might lead to cell apoptosis [33]. ROS production is responsible for apoptosis in acute kidney injury, where it can induce autophagy by alleviating damage to mitochondria [34]. Increased ROS production can reflect the degree of oxidative stress, which is a contributor to CKD development [35]. LC3, which is composed of LC3-I and LC3-II, is a critical marker of autophagy, and LC3 II/I represents the activation of autophagy at the initial stage [36]. In fact, an elevated LC3 II/I ratio represents enhanced autophagy, and Beclin-1 is not only associated with autophagy but also with resistance to apoptosis [37]. Korkmaz et al. reported that upregulated miR$376 \mathrm{~b}$ can directly lower the level of autophagy-related proteins, namely, Atg4C and Beclin-1, the latter of which is of great importance in the activation of autophagy [17].

Accordingly, the present study illuminates potential molecular mechanisms through which the miR-376b downregulation-mediated enhancement of Atg5 triggers the autophagy of macrophages by elevating the protein levels of Beclin-1 and LC3 II/I. miR-376b inhibition leads to the reduction of RIF through the induction of apoptosis and attenuation of the proliferative ability of KFBs by upregulating Bax and caspase- 3 proteins and reducing Bcl2 protein, and the mechanisms are also associated with ROS production (Fig. 8). However, considering the inevitable limitations of our study, much more detailed research is needed in the future. Therefore, this study provides a key target for the treatment of CKD through the study of miR-376b inhibitors. However, further studies are needed to elucidate the specific mechanisms through which miR-376b inhibitors can ameliorate CKD, and a relatively large sample size should be employed.

\section{Acknowledgements}

This study was supported by National Natural Science Foundation of China (81560121). We acknowledge and appreciate our colleagues for their valuable efforts and comments on this paper. 


\section{Kidney \\ Bloód Pressure Research} \begin{tabular}{l|l}
\hline Kidney Blood Press Res 2018;43:1749-1764 \\
\hline $\begin{array}{l}\text { DOI: 10.1159/000495394 } \\
\text { Published online: 23 November 2018 }\end{array}$ & $\begin{array}{l}\text { ○ 2018 The Author(s). Published by S. Karger AG, Basel } \\
\text { www.karger.com/kbr }\end{array}$ \\
\hline
\end{tabular}

\section{Disclosure Statement}

The authors declare they have no conflicts of interest.

\section{References}

1 Ekiti ME, Zambo JB, Assah FK, Agbor VN, Kekay K, Ashuntantang G: Chronic kidney disease in sugarcane workers in Cameroon: a cross-sectional study. BMC Nephrol 2018;19:10.

- Hu J, Iragavarapu S, Nadkarni GN, Huang R, Erazo M, Bao X, Verghese D, Coca S, Ahmed MK, Peter I: Location-Specific Oral Microbiome Possesses Features Associated With CKD. Kidney Int Rep 2018;3:193204.

- Nieto JA, Zhu J, Duan B, Li J, Zhou P, Paka L, Yamin MA, Goldberg ID, Narayan P: A modified elliptical formula to estimate kidney collagen content in a model of chronic kidney disease. PLoS One 2018;13:e0190815.

4 Demirjian S, Lane BR, Derweesh IH, Takagi T, Fergany A, Campbell SC: Chronic kidney disease due to surgical removal of nephrons: relative rates of progression and survival. J Urol 2014;192:1057-1062.

5 Almualm Y, Zaman Huri H: Chronic kidney disease screening methods and its implication for Malaysia: an in depth review. Glob J Health Sci 2015;7:96-109.

6 Venuthurupalli SK, Hoy WE, Healy HG, Cameron A, Fassett RG: CKD Screening and Surveillance in Australia: Past, Present, and Future. Kidney Int Rep 2018;3:36-46.

7 Yan J, Zhang Z, Jia L, Wang Y: Role of Bone Marrow-Derived Fibroblasts in Renal Fibrosis. Front Physiol 2016;7:61.

-8 Guiteras R, Sola A, Flaquer M, Hotter G, Torras J, Grinyo JM, Cruzado JM: Macrophage Overexpressing NGAL Ameliorated Kidney Fibrosis in the UUO Mice Model. Cell Physiol Biochem 2017;42:1945-1960.

-9 Chen L, Sha ML, Li D, Zhu YP, Wang XJ, Jiang CY, Xia SJ, Shao Y: Relaxin abrogates renal interstitial fibrosis by regulating macrophage polarization via inhibition of Toll-like receptor 4 signaling. Oncotarget 2017;8:21044-21053.

10 Wang YY, Jiang H, Pan J, Huang XR, Wang YC, Huang HF, To KF, Nikolic-Paterson DJ, Lan HY, Chen JH: Macrophage-to-Myofibroblast Transition Contributes to Interstitial Fibrosis in Chronic Renal Allograft Injury. J Am Soc Nephrol 2017;28:2053-2067.

11 Metzinger-Le Meuth V, Burtey S, Maitrias P, Massy ZA, Metzinger L: microRNAs in the pathophysiology of CKD-MBD: Biomarkers and innovative drugs. Biochim Biophys Acta 2017;1863:337-345.

12 Gomez IG, Nakagawa N, Duffield JS: MicroRNAs as novel therapeutic targets to treat kidney injury and fibrosis. Am J Physiol Renal Physiol 2016;310:F931-944.

13 Trionfini P, Benigni A, Remuzzi G: MicroRNAs in kidney physiology and disease. Nat Rev Nephrol 2015;11:23-33.

14 Deng X, Xie Y, Zhang A: Advance of autophagy in chronic kidney diseases. Ren Fail 2017;39:306-313.

-15 Festa BP, Chen Z, Berquez M, Debaix H, Tokonami N, Prange JA, Hoek GV, Alessio C, Raimondi A, Nevo N, Giles RH, Devuyst O, Luciani A: Impaired autophagy bridges lysosomal storage disease and epithelial dysfunction in the kidney. Nat Commun 2018;9:161.

-16 Fu LL, Wen X, Bao JK, Liu B: MicroRNA-modulated autophagic signaling networks in cancer. Int J Biochem Cell Biol 2012;44:733-736.

17 Korkmaz G, le Sage C, Tekirdag KA, Agami R, Gozuacik D: miR-376b controls starvation and mTOR inhibition-related autophagy by targeting ATG4C and BECN1. Autophagy 2012;8:165-176.

-18 Tekirdag KA, Korkmaz G, Ozturk DG, Agami R, Gozuacik D: miR181A regulates starvation- and rapamycininduced autophagy through targeting of ATG5. Autophagy 2013;9:374-385.

19 Wang N, Yang L, Zhang H, Lu X, Wang J, Cao Y, Chen L, Wang X, Cong L, Li J, Wang N, Liu Z, Wang L: MicroRNA-9a-5p Alleviates Ischemia Injury After Focal Cerebral Ischemia of the Rat by Targeting ATG5Mediated Autophagy. Cell Physiol Biochem 2018;45:78-87.

20 Xu J, Xia L, Shang Q, Du J, Zhu D, Wang Y, Bi D, Song J, Ma C, Gao C, Zhang X, Sun Y, Zhu L, Wang X, Zhu C, Xing Q: A Variant of the Autophagy-Related 5 Gene Is Associated with Child Cerebral Palsy. Front Cell Neurosci 2017;11:407. 


\section{Kidney \\ Blood Pressure Research}

Yang et al.: miR-376b Targeting Atg5 Modulates RIF in CKD

-21 Li H, Peng X, Wang Y, Cao S, Xiong L, Fan J, Wang Y, Zhuang S, Yu X, Mao H: Atg5-mediated autophagy deficiency in proximal tubules promotes cell cycle G2/M arrest and renal fibrosis. Autophagy 2016;12:1472-1486.

22 Viau A, El Karoui K, Laouari D, Burtin M, Nguyen C, Mori K, Pillebout E, Berger T, Mak TW, Knebelmann B, Friedlander G, Barasch J, Terzi F: Lipocalin 2 is essential for chronic kidney disease progression in mice and humans. J Clin Invest 2010;120:4065-4076.

-23 Kawaguchi A, Utsumi N, Morita M, Ohya A, Wada S: Application of the cis-regulatory region of a heat-shock protein 70 gene to heat-inducible gene expression in the ascidian Ciona intestinalis. Genesis 2015;53:170182.

-24 Cocchiaro P, De Pasquale V, Della Morte R, Tafuri S, Avallone L, Pizard A, Moles A, Pavone LM: The Multifaceted Role of the Lysosomal Protease Cathepsins in Kidney Disease. Front Cell Dev Biol 2017;5:114.

-25 Glassock RJ, Warnock DG, Delanaye P: The global burden of chronic kidney disease: estimates, variability and pitfalls. Nat Rev Nephrol 2017;13:104-114.

-26 Lytle JR, Yario TA, Steitz JA: Target mRNAs are repressed as efficiently by microRNA-binding sites in the 5' UTR as in the 3' UTR. Proc Natl Acad Sci U S A 2007;104:9667-9672.

27 Petrillo F, Iervolino A, Zacchia M, Simeoni A, Masella C, Capolongo G, Perna A, Capasso G, Trepiccione F: MicroRNAs in Renal Diseases: A Potential Novel Therapeutic Target. Kidney Dis (Basel) 2017;3:111-119.

28 Lorenzen JM, Haller H, Thum T: MicroRNAs as mediators and therapeutic targets in chronic kidney disease. Nat Rev Nephrol 2011;7:286-294.

-29 Sun Q, Miao J, Luo J, Yuan Q, Cao H, Su W, Zhou Y, Jiang L, Fang L, Dai C, Zen K, Yang J: The feedback loop between miR-21, PDCD4 and AP-1 functions as a driving force for renal fibrogenesis. J Cell Sci 2018;131:pii:jcs202317.

-30 Livingston MJ, Ding HF, Huang S, Hill JA, Yin XM, Dong Z: Persistent activation of autophagy in kidney tubular cells promotes renal interstitial fibrosis during unilateral ureteral obstruction. Autophagy 2016;12:976-998.

-31 Kitamoto K, Machida Y, Uchida J, Izumi Y, Shiota M, Nakao T, Iwao H, Yukimura T, Nakatani T, Miura K: Effects of liposome clodronate on renal leukocyte populations and renal fibrosis in murine obstructive nephropathy. J Pharmacol Sci 2009;111:285-292.

32 Shi M, Flores B, Gillings N, Bian A, Cho HJ, Yan S, Liu Y, Levine B, Moe OW, Hu MC: alphaKlotho Mitigates Progression of AKI to CKD through Activation of Autophagy. J Am Soc Nephrol 2016;27:2331-2345.

33 Takahashi A, Kimura T, Takabatake Y, Namba T, Kaimori J, Kitamura H, Matsui I, Niimura F, Matsusaka T, Fujita N, Yoshimori T, Isaka Y, Rakugi H: Autophagy guards against cisplatin-induced acute kidney injury. Am J Pathol 2012;180:517-525.

34 Sunahara S, Watanabe E, Hatano M, Swanson PE, Oami T, Fujimura L, Teratake Y, Shimazui T, Lee C, Oda S: Influence of autophagy on acute kidney injury in a murine cecal ligation and puncture sepsis model. Sci Rep 2018;8:1050.

35 Liu BC, Tang TT, Lv LL, Lan HY: Renal tubule injury: a driving force toward chronic kidney disease. Kidney Int 2018;93:568-579.

-36 Su Z, Klein JD, Du J, Franch HA, Zhang L, Hassounah F, Hudson MB, Wang XH: Chronic kidney disease induces autophagy leading to dysfunction of mitochondria in skeletal muscle. Am J Physiol Renal Physiol 2017;312:F1128-F1140.

37 Qiu Y, Li C, Wang Q, Zeng X, Ji P: Tanshinone IIA induces cell death via Beclin-1-dependent autophagy in oral squamous cell carcinoma SCC-9 cell line. Cancer Med 2018;7:397-407. 